\title{
A microsatellite-based analysis for the detection of selection on BTA1 and BTA20 in northern Eurasian cattle (Bos taurus) populations
}

Meng-Hua Li, Terhi Iso-Touru, Hannele Laurén, Juha Kantanen*

\begin{abstract}
Background: Microsatellites surrounding functionally important candidate genes or quantitative trait loci have received attention as proxy measures of polymorphism level at the candidate loci themselves. In cattle, selection for economically important traits is a long-term strategy and it has been reported that microsatellites are linked to these important loci.
\end{abstract}

Methods: We have investigated the variation of seven microsatellites on BTA1 (Bos taurus autosome 1) and 16 on BTA20, using bovine populations of typical production types and horn status in northern Eurasia. Genetic variability of these loci and linkage disequilibrium among these loci were compared with those of 28 microsatellites on other bovine chromosomes. Four different tests were applied to detect molecular signatures of selection.

Results: No marked difference in locus variability was found between microsatellites on BTA1, BTA20 and the other chromosomes in terms of different diversity indices. Average $D^{\prime}$ values of pairwise syntenic markers (0.32 and 0.28 across BTA 1 and BTA20 respectively) were significantly $(P<0.05)$ higher than for non-syntenic markers $(0.15)$. The Ewens-Watterson test, the Beaumont and Nichol's modified frequentist test and the Bayesian $F_{S T}$ test indicated elevated or decreased genetic differentiation, at SOD1 and AGLA17 markers respectively, deviating significantly $(P<$ 0.05) from neutral expectations. Furthermore, InRV, InRH and InR $\theta^{\prime}$ statistics were used for the pairwise population comparison tests and were significantly less variable in one population relative to the other, providing additional evidence of selection signatures for two of the 51 loci. Moreover, the three Finnish native populations showed evidence of subpopulation divergence at SOD1 and AGLA17. Our data also indicate significant intergenic linkage disequilibrium around the candidate loci and suggest that hitchhiking selection has played a role in shaping the pattern of observed linkage disequilibrium.

Conclusion: Hitchhiking due to tight linkage with alleles at candidate genes, e.g. the POLL gene, is a possible explanation for this pattern. The potential impact of selective breeding by man on cattle populations is discussed in the context of selection effects. Our results also suggest that a practical approach to detect loci under selection is to simultaneously apply multiple neutrality tests based on different assumptions and estimations.

\section{Background}

Expectation of neutrality regarding the mutation-drift equilibrium for microsatellite variation is not always valid due to demographic changes, including genetic bottlenecks and admixture (e.g. [1,2]), and selection at linked sites (e.g. [3,4]). In contrast to demographic processes, which affect the entire genome, selection

\footnotetext{
* Correspondence: juha.kantanen@mtt.fi
Biotechnology and Food Research, MTT Agrifood Research Finland, Fl-31600

* Correspondence: juha.kantanen@mtt.fi
Biotechnology and Food Research, MTT Agrifood Research Finland, Fl-31600 Jokioinen, Finland
}

(c) $2010 \mathrm{Li}$ et al; licensee BioMed Central Ltd. This is an Open Access article distributed under the terms of the Creative Commons Attribution License (http://creativecommons.org/licenses/by/2.0), which permits unrestricted use, distribution, and reproduction in any medium, provided the original work is properly cited. traits, such as important quantitative trait loci (QTLs) and candidate genes. Selection leaves its signature in the chromosomal regions surrounding the sites, where significantly reduced or elevated levels of genetic variation can be maintained at linked neutral loci. Thus, selection not only affects the selected sites but also linked neutral loci and the footprints of selection acting on specific functional loci can be detected by genotyping polymorphic microsatellites in the adjacent non-coding regions [5]. 
Different statistical methods have been developed to identify outlier loci under the influence of selection [6-13] and adaptations have been attempted to improve the original methods of Lewontin and Krakauer [14], which have been criticized because of their sensitivity to population structure and history (e.g. [15]). Nevertheless, recent studies have shown somewhat inconsistent results obtained by applying the above statistical tests to the same data (e.g. $[7,12,16,17])$. The Lewontin- Krakauer test [14] is the oldest of these multilocus-comparison methods. Broadly speaking, these methods are derived by using one of the two general approaches detailed below. The first approach is to develop methods with Lewontin and Krakauers' original idea and to use the distribution of estimates of genetic differentiation coefficient $F_{\mathrm{ST}}$ and diversity parameters from individual genetic loci to detect the effects of selection, hereafter termed the $F_{\mathrm{ST}}$-based approach, such as the FDIST program-based method [9], Bayesian regression [12], and population-specific [7] methods. Schlötterer and colleagues have proposed alternative multilocus simulationbased tests that use summary statistics other than $F_{\mathrm{ST}}$, such as the $\ln \mathrm{RV}$ [10], the $\ln \mathrm{RH}$ [6], and the $\ln \mathrm{R} \theta$ ' [13] tests. These tests involve considering the idea of a 'selective sweep' that arises from natural and artificial selection, and recent genetic exchanges driven by the selective sweep leave a record or "genetic signature" in the genome covering the selected sites and their linked neutral loci. Given that microsatellite loci associated with a recent selective sweep differ from the remainder of the genome, they are expected to fall outside the distribution of neutral estimates of $\ln \mathrm{RV}, \ln \mathrm{RH}$ or $\ln \mathrm{R} \theta$ ' values. As reviewed by [18-20], all the methods have potential advantages and drawbacks, which can be due to different underlying assumptions regarding the demographic and mutational models on which they are based, as well as on uncertainty associated with the robustness of the approaches.

The recent increased availability of large genomic data sets and the identification of a few genes or loci as the targets of domestication or subsequent genetic improvement in cattle have renewed the investigation of the genomic effects of selection. Candidate genes and QTL have been described on both BTA1 [21-25] and BTA 20 [26]. On BTA1, the POLL gene, characterized by two alleles: $P$ (polled) dominant over $H$ (horn), is responsible for the polled (i.e. hornless) and horn phenotypes in cattle and has been subjected to both natural and artificial selection. Georges et al. [21] have demonstrated genetic linkage between the POLL gene and two microsatellites, GMPOLL-1 and GMPOLL-2. These loci are syntenic to the highly conserved gene for superoxide dismutase 1 (SOD1). In addition, in various breeds the POLL gene has been found to be linked to the microsatellites
TGLA49, AGLA17, INRA212 and KAP8, located in the centromeric region of BTA1 close to the SOD1 locus $[22,23,25]$. To date, on BTA20 several QTL and candidate genes have been reported e.g. growth hormone and prolactin receptor genes [27] affecting conformation and milk production traits, such as body depth (e.g. [28]), udder (e.g. [29]), udder attachment (e.g. [30]), milk yield (e.g. [31]), fat percentage (e.g. [28]), and especially protein content (e.g. [28-30]).

In this study on Bos taurus, we present microsatellite data using a relatively larger number of loci than previously reported, which mainly included the 30 microsatellite markers recommended by the International Society for Animal Genetics (ISAG)/Food and Agriculture Organization of the United Nations (FAO) working group (e.g. [2,24]; but see also [32]). Among the 51 microsatellites genotyped on 10 representative cattle populations of different origins (native and modern commercial) and horn statuses (polled and horned) in the northern territory of the Eurasian subcontinent, seven were on BTA1 and 16 on BTA20. We applied four tests to detect molecular signatures of selection, ranging from tests for loci across populations and the recently proposed pairwise population tests using a dynamically adjusted number of linked microsatellites [13]. We compared the consistency of the different neutrality tests available to identify loci under selection in the north Eurasian cattle populations investigated here.

\section{Materials and methods}

\section{Population samples and genetic markers}

Microsatellite data from 10 different cattle (Bos taurus) populations including 366 individuals were analyzed. Finnish populations were represented by Finnish Ayrshire (modern commercial, horned, $n=40$ ), Finnish Holstein-Friesian (modern commercial, horned, $n=40$ ), Eastern Finncattle (native, mostly polled, $n=31$ ), Western Finncattle (native, mostly polled, $n=37$ ), and Northern Finncattle (native, mostly polled, $n=26$ ). We were able to inference the heterozygotic status at the POLL locus in 19 phenotypically polled cattle of the three Finnish native populations, on the basis of their offspring/parent phenotypes. In addition, there were 19 animals horned (recessive homozygotic) in the Finnish native populations. Istoben (native, horned, $n=40$ ), Yakutian (native, horned, $n=51$ ), and Kholmogory (native, horned, $n=32$ ) cattle were sampled in Russia. Ukrainian Grey (native, horned, $n=30$ ) and Danish Jersey (modern commercial, horned, $n=39$ ) were sampled in Ukraine and Denmark, respectively. During sample collection, the pedigree information and the herdsman's knowledge were used to ensure the animals were unrelated. Additional information on these populations has been reported in previous publications [2,33]. 
Genotypes of the 51 microsatellites were used (for details on the microsatellites, see [33-35]) among which data of the 30 markers from the panel of loci recommended for genetic diversity studies in cattle http:// www.projects.roslin.ac.uk/cdiv/markers.html were taken from the literature [2]. The 23 microsatellites (21 new ones and two from the recommended panel) on BTA1 and BTA20 were chosen on the basis of their vicinity to genes and QTL, which could be considered as candidate loci for selection because of their assumed involvement in the polled/horned phenotype [22] and in milk yield and body composition [35]. Details of the primers and microsatellite analysis protocols can be found in $\mathrm{CaD}$ Base http://www.projects.roslin.ac.uk/cdiv/markers.html and [34]. In this study, GHRJA.UP, 5'GGTTCGTTATGGAGGCAATG-3', and GHRJA.DN, 5'-GTCACCGCTGGCAGTAGAT-3' primers were designed based on the sequence of the promoter region of the growth hormone receptor gene [35] containing microsatellite GHRJA. Danish Jersey animals were analyzed only at 41 loci (see Table 1). A full list of the loci studied and their chromosomal and genomic locations, as well as population and basic statistics, are available in Table 1.

\section{Microsatellite variability measures and test for linkage disequilibrium}

Microsatellite variability, expected heterozygosity $\left(H_{\mathrm{EXP}}\right)$, allelic richness $\left(A_{\mathrm{R}}\right)$, and Weir and Cockerham's $F_{\mathrm{ST}}$ [36], were estimated with the FSTAT program, version 2.9.3.2 [37].

The $D^{\prime}$ metric used to estimate the LD was calculated using Multiallelic Interallelic Disequilibrium Analysis Software (MIDAS; [38]). Values of $D^{\prime}$ were calculated for all syntenic marker pairs on BTA1 and BTA20 across the populations. A more detailed description of the estimation of $D^{\prime}$ can be found in [39]. The statistical significance of the observed association between pairs of alleles under the null hypothesis of random allelic assortment was tested using a Monte-Carlo approximation of Fisher's exact test as implemented in the software ARLEQUIN [40] using a Markov chain extension to Fisher's exact test for $R \times C$ contingency tables [41] A total of 100000 alternative tables were explored with the Markov chain and probabilities were typically estimated with a standard error of $<0.001$. Estimation of the $D^{\prime}$ metric for LD and tests for their significance were conducted only in three Finnish native breeds, i.e. Northern Finncattle, Eastern Finncattle and Western Finncattle. The graphic summary of the significance of LD determinations was displayed using the HaploView program, version 4.0 [42]. Fisher's exact tests in the GENEPOP v 4.0 [43] were applied to assess LD determinations between all locus pairs across the sample.
Tests to detect loci under selection across populations Possible departures from the standard neutral model of molecular evolution - potentially revealing demographic events or the existence of selective effects at certain loci - were examined for each locus using the EwensWatterson test $[44,45]$ and the Beaumont and Nichols's modified frequentist method [9], as well as a more robust Bayesian test [12].

The Ewens-Watterson test of neutrality was performed with the ARLEQUIN program [40] assuming an infinite allele mutation model. To obtain sufficient precision with this test, the probability was recorded as the mean of 20 independent repeats of 1,000 simulations. The frequentist method used was that proposed by [9], further developed by [12], and implemented in the FDIST2 program http://www.rubic.rdg.ac.uk/ mab/ software.html, a currently distributed version of the original FDIST program as described by [12]. FDIST2 calculates $\theta$, Weir \& Cockerham's [36] estimator of diversity for each locus in the sample. Coalescent simulations are then performed to generate data sets with a distribution of $\theta$ centered on the empirical estimates. Then, the quantiles of the simulated $F_{\mathrm{ST}}$ within which the observed $F_{\mathrm{ST}}$ 's fell and the $P$-values for each locus were determined. Initially an island model of population differentiation was used and the procedure repeated 50,000 times to generate $95 \%$ confidence intervals for neutral differentiation and to estimate $P$-values for departure of the loci from these expectations. Simulation parameters were under an infinite allele mutation model for 100 demes, 10 sample populations, sample sizes of 100 , and a weighted $F_{\mathrm{ST}}$ similar to the trimmed mean $F_{\mathrm{ST}}$ calculated from the empirical distribution. Computed by removing the $30 \%$ highest and lowest $F_{\mathrm{ST}}$ values observed in the empirical data set, the trimmed mean $F_{\mathrm{ST}}$ is an estimate of the average "neutral" $F_{\mathrm{ST}}$ value uninfluenced by outlier loci (see [46]). This method provides evidence for selection by looking for outliers with higher/lower observed $F_{\mathrm{ST}}$-values, controlling for $P$-values [12]. The approach is fairly robust regarding variation in mutation rate between loci, sample size, and whether populations are at equilibrium or not [9].

Beaumont \& Balding's [12] hierarchical-Bayesian method was performed using the BAYESFST program http://www.reading.ac.uk/Statistics/genetics/software. html package, which generates 2,000 Markov chain Monte Carlo (MCMC) simulated loci on the basis of the distribution of $F_{\mathrm{ST}}$ given the data. The method combines information over loci and populations in order to simultaneously estimate $F_{\mathrm{ST}}$ at the $i^{\text {th }}$ locus and the $j^{\text {th }}$ population, $F_{\mathrm{ST}}(i, j)$, for all $i$ loci and $j$ populations. A hierarchical model is implemented for $F_{\mathrm{ST}}(i, j)$ as 
Table 1 Summary of the microsatellites and basic population genetic estimates for the microsatellites

\begin{tabular}{|c|c|c|c|c|c|c|c|c|c|c|c|c|}
\hline \multirow[t]{2}{*}{ Locus } & \multirow[t]{2}{*}{ BTA } & \multicolumn{2}{|c|}{ Genomic position (bp) } & \multirow[t]{2}{*}{$A_{\mathrm{R}}$} & \multirow[t]{2}{*}{$H_{\mathrm{E}}$} & \multirow[t]{2}{*}{$F_{\mathrm{IS}}$} & \multicolumn{2}{|c|}{ FDIST2 test } & \multicolumn{4}{|c|}{ Ewens-Watterson test } \\
\hline & & starts & ends & & & & $F_{\mathrm{ST}}$ & $P$ & $F_{\text {OBS }}$ & $F_{\mathrm{EXP}}$ & $P_{\mathrm{H}}$ & $P_{\mathrm{E}}$ \\
\hline AGLA17 & 1 & 641402 & 641615 & 1.37 & 0.08 & -0.049 & 0.017 & $0.010^{* *}$ & 0.907 & 0.754 & $0.978^{*}$ & $0.976^{*}$ \\
\hline DIK4591 & 1 & 1704734 & 1705228 & 2.60 & 0.32 & 0.064 & 0.128 & 0.660 & 0.467 & 0.442 & 0.844 & 0.622 \\
\hline DIK1044 & 1 & 2829429 & 2829737 & 4.86 & 0.70 & 0.015 & 0.118 & 0.631 & 0.324 & 0.329 & 0.136 & 0.243 \\
\hline SOD1 & 1 & 2914373 & 2915349 & 4.78 & 0.65 & 0.083 & 0.173 & $0.968^{*}$ & 0.331 & 0.379 & $0.037^{*}$ & $0.047^{*}$ \\
\hline DIK5019 & 1 & 3900549 & 3900808 & 5.42 & 0.59 & 0.190 & 0.164 & $0.954^{*}$ & 0.381 & 0.380 & $0.005^{* *}$ & $0.008^{* *}$ \\
\hline BMS2321 & 1 & 10949260 & 10949302 & 3.58 & 0.45 & 0.154 & 0.094 & 0.410 & 0.429 & 0.486 & 0.424 & 0.052 \\
\hline BM1824 & 1 & 122531990 & 122532171 & 3.95 & 0.72 & -0.083 & 0.122 & 0.655 & 0.450 & 0.487 & $0.030^{*}$ & 0.231 \\
\hline TGLA304 & 20 & 11460907 & 11460992 & 3.30 & 0.49 & 0.113 & 0.114 & 0.573 & 0.497 & 0.531 & 0.237 & 0.238 \\
\hline BMS1754 & 20 & 18439757 & 18439877 & 3.47 & 0.58 & 0.014 & 0.094 & 0.384 & 0.503 & 0.536 & 0.153 & 0.126 \\
\hline NRDIKM033 & 20 & 15598470 & 15598176 & 5.20 & 0.75 & -0.004 & 0.098 & 0.372 & 0.234 & 0.213 & 0.415 & 0.466 \\
\hline ILSTS068 & 20 & 21675187 & 21675451 & 2.07 & 0.25 & 0.095 & 0.146 & 0.760 & 0.734 & 0.751 & 0.383 & 0.223 \\
\hline TGLA126 & 20 & 21808628 & 21808745 & 6.27 & 0.71 & -0.009 & 0.079 & 0.170 & 0.493 & 0.443 & 0.085 & 0.057 \\
\hline BMS2461 & 20 & 25278607 & 25278662 & 4.83 & 0.62 & 0.028 & 0.180 & $0.985^{*}$ & 0.227 & 0.246 & 0.453 & 0.760 \\
\hline BMS1128 & 20 & 26364064 & 26364112 & 3.54 & 0.52 & 0.032 & 0.109 & 0.534 & 0.472 & 0.446 & 0.503 & 0.203 \\
\hline BM713 & 20 & 26977228 & 26977280 & 3.36 & 0.62 & -0.074 & 0.162 & 0.907 & 0.439 & 0.486 & 0.197 & 0.674 \\
\hline DIK2695 & 20 & 30452613 & 30452786 & 3.60 & 0.58 & -0.027 & 0.075 & 0.186 & 0.432 & 0.411 & 0.565 & 0.274 \\
\hline TGLA153 & 20 & 31240022 & 31240154 & 4.64 & 0.71 & 0.025 & 0.109 & 0.521 & 0.345 & 0.353 & 0.101 & 0.269 \\
\hline GHRproms & 20 & 31023202 & 31023306 & 3.12 & 0.43 & 0.006 & 0.114 & 0.581 & 0.426 & 0.446 & 0.726 & 0.268 \\
\hline BMS2361 & 20 & 34597279 & 34597368 & 5.10 & 0.72 & 0.019 & 0.125 & 0.698 & 0.329 & 0.351 & $0.045^{* *}$ & $0.017^{* *}$ \\
\hline DIK4835 & 20 & 35915540 & 35916040 & 4.96 & 0.65 & 0.022 & 0.136 & 0.788 & 0.293 & 0.329 & 0.252 & 0.046 \\
\hline AGLA29 & 20 & 3842995 & 38843142 & 5.49 & 0.78 & -0.006 & 0.087 & 0.202 & 0.363 & 0.412 & $0.000^{* *}$ & $0.000^{* *}$ \\
\hline BMS117 & 20 & 40015465 & 40015564 & 3.88 & 0.67 & -0.018 & 0.078 & 0.197 & 0.377 & 0.376 & 0.398 & 0.272 \\
\hline UMBTL78 & 20 & 40177064 & 40177157 & 4.22 & 0.58 & -0.033 & 0.102 & 0.462 & 0.298 & 0.256 & 0.884 & 0.229 \\
\hline BM2113 & 2 & 88476 & 88616 & 5.44 & 0.79 & -0.052 & 0.119 & 0.673 & 0.353 & 0.379 & $0.003^{* *}$ & $0.005^{* *}$ \\
\hline INRA023 & 3 & 35576043 & 35576259 & 4.85 & 0.70 & 0.009 & 0.113 & 0.564 & 0.309 & 0.306 & 0.238 & 0.107 \\
\hline ETH10 & 5 & 55333999 & 55334220 & 4.57 & 0.67 & 0.002 & 0.134 & 0.789 & 0.432 & 0.446 & $0.049^{*}$ & $0.031^{*}$ \\
\hline ETH152 & 5 & NA & NA & 4.56 & 0.71 & 0.012 & 0.081 & 0.171 & 0.425 & 0.486 & $0.008^{* *}$ & 0.020 \\
\hline ILSTS006 & 7 & 86555402 & 86555693 & 5.14 & 0.77 & -0.007 & 0.076 & 0.110 & 0.331 & 0.351 & $0.032^{*}$ & 0.057 \\
\hline HEL9 & 8 & NA & NA & 5.04 & 0.70 & 0.020 & 0.134 & 0.792 & 0.262 & 0.289 & 0.240 & 0.245 \\
\hline ETH225 & 9 & 8089454 & 8089601 & 5.02 & 0.71 & 0.013 & 0.113 & 0.560 & 0.410 & 0.478 & $0.009^{* *}$ & $0.009^{* *}$ \\
\hline MM12 & 9 & NA & NA & 7.76 & 0.67 & 0.017 & 0.123 & 0.671 & 0.312 & 0.347 & 0.244 & 0.112 \\
\hline ILSTS005 & 10 & 93304132 & 93304315 & 2.17 & 0.43 & -0.026 & 0.083 & 0.356 & 0.686 & 0.664 & 0.358 & 0.390 \\
\hline CSRM60 & 10 & 70549981 & 70550081 & 7.03 & 0.72 & 0.011 & 0.073 & 0.094 & 0.405 & 0.418 & $0.046^{*}$ & $0.038^{*}$ \\
\hline HEL13 & 11 & NA & NA & 3.14 & 0.51 & 0.081 & 0.125 & 0.678 & 0.402 & 0.407 & 0.529 & 0.564 \\
\hline INRA032 & 11 & 49569411 & 49569592 & 3.81 & 0.62 & -0.010 & 0.142 & 0.812 & 0.511 & 0.537 & 0.063 & 0.016 \\
\hline INRA037 & 11 & 70730695 & 70730819 & 4.54 & 0.58 & 0.030 & 0.129 & 0.717 & 0.266 & 0.243 & 0.830 & 0.462 \\
\hline INRA005 & 12 & 71751518 & 71751656 & 3.18 & 0.56 & 0.032 & 0.088 & 0.321 & 0.594 & 0.596 & 0.114 & 0.096 \\
\hline CSSM66 & 14 & 6128576 & 6128773 & 5.91 & 0.74 & 0.002 & 0.137 & 0.873 & 0.312 & 0.352 & $0.000^{* *}$ & $0.003^{* *}$ \\
\hline HEL1 & 15 & NA & NA & 3.99 & 0.67 & 0.020 & 0.072 & 0.138 & 0.468 & 0.445 & 0.119 & 0.155 \\
\hline SPS115 & 15 & NA & NA & 5.40 & 0.58 & 0.039 & 0.096 & 0.416 & 0.478 & 0.482 & 0.228 & 0.146 \\
\hline INRA035 & 16 & 62926476 & 62926577 & 2.72 & 0.23 & 0.391 & 0.072 & 0.266 & 0.521 & 0.488 & 0.746 & 0.421 \\
\hline TGLA53 & 16 & 22214785 & 22214925 & 12.25 & 0.74 & 0.071 & 0.099 & 0.354 & 0.195 & 0.213 & 0.063 & 0.037 \\
\hline ETH185 & 17 & 36598852 & 36599086 & 8.31 & 0.68 & 0.039 & 0.146 & 0.877 & 0.336 & 0.303 & 0.186 & 0.196 \\
\hline INRA063 & 18 & 37562469 & 37562645 & 3.31 & 0.57 & 0.031 & 0.110 & 0.546 & 0.537 & 0.487 & 0.270 & 0.135 \\
\hline TGLA227 & 18 & 60360145 & 60360234 & 10.71 & 0.82 & 0.005 & 0.076 & 0.075 & 0.282 & 0.315 & $0.005^{* *}$ & $0.012^{*}$ \\
\hline ETH3 & 19 & NA & NA & 4.44 & 0.65 & 0.009 & 0.135 & 0.787 & 0.407 & 0.406 & 0.073 & 0.139 \\
\hline HEL5 & 21 & 11850292 & 11850455 & 4.64 & 0.66 & 0.038 & 0.151 & 0.903 & 0.424 & 0.410 & $0.023^{*}$ & 0.104 \\
\hline TGLA122 & 21 & 50825795 & 50825936 & 11.36 & 0.74 & 0.007 & 0.069 & 0.065 & 0.210 & 0.213 & 0.538 & 0.152 \\
\hline
\end{tabular}


Table 1 Summary of the microsatellites and basic population genetic estimates for the microsatellites (Continued)

\begin{tabular}{lllllllllllll}
\hline HAUT24 & 22 & 45733839 & 45733962 & 7.09 & 0.70 & 0.025 & 0.143 & 0.861 & 0.406 & 0.424 & $0.004^{* *}$ & $0.027^{*}$ \\
BM1818 & 23 & 35634770 & 35635033 & 4.03 & 0.63 & 0.019 & 0.102 & 0.458 & 0.538 & 0.486 & 0.144 & $0.013^{*}$ \\
HAUT27 & 26 & 26396836 & 26396987 & 8.85 & 0.61 & 0.126 & 0.103 & 0.453 & 0.376 & 0.396 & 0.083 & $0.003^{* *}$ \\
\hline
\end{tabular}

BTA, Bos taurus autosome; $A_{R}$, allelic richness; $H_{E}$, expected heterozygosity, $F_{I S}$, inbreeding coefficient, observed homozygosity, $F_{\mathrm{OBS}}$, and expected homozygosity, $F_{\mathrm{EXP}}, \mathrm{NA}$, not available; the probabilities for the Ewens-Watterson test were calculated based on homozygosity $\left(P_{\mathrm{H}}\right)$ or Fishers's exact test $\left(P_{\mathrm{E}}\right) ;{ }^{*}$, the significance level of $P<0.05, * *$, the significance level of $P<0.01$; the genomic positions for the loci are BLASTed against STS or primer sequence in ENSEMBL cow genome Btau4.0 http://www.ensembl.org/Bos_taurus/Info/Index updated until 11/02/2010

$$
F_{\mathrm{ST}}(i, j)=\frac{\exp (\alpha i+\beta i+\gamma i)}{1+\exp (\alpha i+\beta i+\gamma i)}
$$

where $\alpha_{\mathrm{i}}, \beta_{\mathrm{j}}$ and $\gamma_{\mathrm{ij}}$ are locus, population and locus-bypopulation parameters, respectively [12]. In this study, the interpretations of the potential outliers are based on the locus effect $\left(\alpha_{\mathrm{i}}\right)$. Outliers from our data set were identified on the basis of the distribution following [12]. Rather than a fixed $F_{\mathrm{ST}}$ as assumed in the above frequentist method of [9], this BAYESFST test uses more information from the raw data and does not assume the same $F_{\mathrm{ST}}$ for each population $[5,12]$.

\section{Tests to detect loci under selection for pairwise populations}

To test for additional evidence of selection, we used the combination of statistics $\ln R H, \ln R V$ and $\ln R \theta^{\prime}$ in the population pairwise comparisons. The principle behind these tests is that variability at a neutral microsatellite locus is given by $\theta=4 N_{\mathrm{e}} \mu$, where $N_{\mathrm{e}}$ is the effective population size and $\mu$ is the mutation rate. A locus linked to a beneficial mutation will have a smaller effective population size and consequently a reduction in variability below neutral expectations. The relative variance in variability, $\ln R \theta$, can be assessed instead by estimating the relative variance in repeat number, $\ln R \mathrm{~V}$, or heterozygosity, $\ln \mathrm{RH}$, for loci between populations. The $\ln \mathrm{RV}$ was calculated using the equation $\ln \mathrm{RV}=\ln$ ( $V_{\text {pop1 }} / V_{\text {pop2 }}$ ) where $V_{\text {pop1 }}$ and $V_{\text {pop2 }}$ are the variance in repeat number for population 1 and population 2, respectively [10]. The $\ln R H$ test is based on the calculation of the logarithm of the ratio of $H$ for each locus for a pair of populations as follows

$$
\ln \mathrm{RH}=\ln \frac{\left(\frac{1}{1-H_{\mathrm{pop} 1}}\right)^{2}-1}{\left(\frac{1}{1-H_{\mathrm{pop} 2}}\right)^{2}-1}
$$

where $H$ denotes expected heterozygosity (see equation 2 in [6]). In addition, we attempted to calculate ln $\mathrm{R} \theta$ by estimating $\theta$ directly using a coalescence-based
Bayesian Markov chain Monte Carlo simulation approach employing the MSVAR program [47].

The tests have been shown to be relatively insensitive to mutation rate, deviation from the stepwise mutation model, demographic history of population and sample size [16]. As suggested by [48], to detect the most recent and strong selective sweeps, the combination of $\ln R H$ and $\ln R V$ statistics is as powerful as $\ln R V$ alone, but using both statistics together lowers the rate of false positives by a factor of 3 because the variance in repeat number and the heterozygosity of a population measure different aspects of the variation at a locus. Thus, combinations of any two of the three tests were implemented here and significance of $\ln R H, \ln R V$ and $\ln R \theta^{\prime}$ for each comparison was calculated according to standard methods $[6,10,48]$. These statistics are generally normally distributed, and simulations have confirmed that outliers (e.g. more than 1.96/2.58 standard deviations from the mean for $95 \% / 99 \%$ confidence intervals, respectively) are likely to be caused by selection [48]. The tests were implemented for every pairwise comparison involving native populations from different trait categories (Eastern Finncattle, Western Finncattle and Northern Finncattle vs. Yakutian, Istoben, Kholmogory and Ukrianian Grey), i.e. 12 population pairs for the horn (polled/horned) trait.

\section{Tests to detect loci under selection within a population}

The coalescence simulation approach using the DetSel 1.0 program [49] was used to detect outlier loci within the Finnish native populations (Eastern Finncattle, Western Finncattle and Northern Finncattle). It has the advantage of being able to take into account a wide range of potential parameters simultaneously and giving results that are robust regarding the starting assumptions. For each pair of populations $(i, j)$, and for all loci, we calculated $F_{\mathrm{i}}$ and $F_{\mathrm{j}}\left(F_{\mathrm{i}}\right.$ and $F_{\mathrm{j}}$ are the populationspecific divergence; for details see $[7,49]$ ) and generated the expected joint distribution of $F_{\mathrm{i}}$ and $F_{\mathrm{j}}$ by performing 10,000 coalescent simulations. Thus, every locus falling outside the resulting confidence envelope can be seen as potentially under selection. The following nuisance parameters were used to generate null distributions with similar numbers of allelic stages as in the 
observed data set: mutation rates (infinite allele model) $\mu=1 \times 10^{-2}, 1 \times 10^{-3}$, and $1 \times 10^{-4}$; ancestor population size $N_{\mathrm{e}}=500,5,000$, and 50,000; times since an assumed bottleneck event $T_{0}=50,500$, and 5,000 generations; time since divergence $t=50$ and 500; and population size before the split $N_{0}=50$ and 500 . In order to detect outlier loci potentially selected for the polled trait within the three Finnish native cattle populations, the DetSel program was run for comparison between the two subpopulations representing the definitely polled $(n=19)$ and horned $(n=19)$ animals, respectively.

\section{Results}

\section{Genetic diversity and differentiation}

A complete list of loci and their variability in the 10 cattle populations are shown in Table 1 . The overall genetic differentiation across loci was $0.117\left(F_{\mathrm{ST}}=\right.$ $0.117,95 \%$ CI $0.108-0.125)$. $F_{\mathrm{ST}}$ values for an individual locus varied from $0.017(\mathrm{SD}=0.011)$ at $A G L A 17$ on BTA1 to $0.180(\mathrm{SD}=0.057)$ at BMS2461 on BTA20. Mean population differentiations for loci on BTA1 and BTA20 were $0.126\left(F_{\mathrm{ST}}=0.126,95 \%\right.$ CI $\left.0.103-0.143\right)$ and $0.118\left(F_{\mathrm{ST}}=0.118,95 \%\right.$ CI $\left.0.100-0.139\right)$, respectively. Neither of the values indicated significant difference from the average for loci on other chromosomes $\left(F_{\mathrm{ST}}=0.114,95 \%\right.$ CI $\left.0.104-0.124\right)$.

Levels of variation across populations, including allelic richness $\left(A_{\mathrm{R}}\right)$ and expected heterozygosity $\left(H_{\mathrm{E}}\right)$, were in similar ranges as for microsatellites on BTA1, BTA20 and other autosomes, with the smallest variations observed at $A G L A 17\left(A_{\mathrm{R}}=1.37, H_{\mathrm{E}}=0.08\right)$. The highest $H_{\mathrm{E}}$ of 0.79 was observed at BM2113 (BTA2) and the highest $A_{\mathrm{R}}$ of 11.36 at TGLA122 (BTA21). Most $F_{\mathrm{IS}}$ values were positive and for some loci significantly positive. Of the 13 negative $F_{\text {IS }}$ values, seven occurred for loci on BTA20, and two for loci on BTA1. Loci on BTA1 and BTA20 did not show a significant reduction or increase in mean $F_{\mathrm{IS}}$ compared with the loci on other autosomes (other bovine autosomes, mean $F_{\mathrm{IS}}=0.038$; BTA1, mean $F_{\mathrm{IS}}=0.053$, Mann-Whitney test $U=118$, $P=0.409$; BTA20, mean $F_{\mathrm{IS}}=0.011$, Mann-Whitney test $U=273.5, P=0.227$ ). Given the range of observations of $F_{\mathrm{IS}}$ at an individual locus, there were no marked difference among the three classes of loci (BTA1, -0.083 - 0.190; BTA20, -0.074 - 0.113; other BTAs, -0.052 $0.391)$.

\section{Linkage disequilibrium}

The strength of pairwise linkage disequilibrium (LD) between markers was estimated and the average $D^{\prime}$ value of pairwise syntenic markers was 0.32 across BTA1 and 0.28 across BTA20, both of which are significantly $(P<0.05)$ higher than for non-syntenic markers (0.15; only the $D^{\prime}>0.3$ are shown in Figure 1$)$. Figure 1 also shows matrices of LD significance levels for all possible locus combinations of the loci on BTA1 or BTA20 in their chromosomal order. Of the 120 pairwise comparisons of the 16 loci on BTA20, a total of $22(22 / 120$, $18.3 \%$ ) tests showed $P$ values below 0.05 . Likewise, LD between markers on BTA1 provided seven (7/21, 33.3\%) significant observations. However, a substantially smaller proportion $(34 / 1124,3.0 \%)$ of significant $(P<0.05)$ pairs was found between non-syntenic markers. In general, significantly higher levels of LD were observed for syntenic markers on BTA1 and BTA20 than that for nonsyntenic markers. There was no evidence of LD blocks on either of the chromosomes.

\section{Evidence for selection across the populations}

The Ewens-Watterson test enables detection of deviations from a neutral-equilibrium model as either a deficit or an excess of genetic diversity relative to the number of alleles at a locus (see [50]). When applying the tests for all the microsatellites, we detected 13 loci (AGLA17, DIK5019, SOD1, AGLA29, BMS2361, BM2113, ETH10, ETH225, CSSM66, ETH152, TGLA227, HAUT24, and CSRM60) on 10 different chromosomes exhibiting significant probabilities for the Ewens-Watterson test based on both homozygosity $\left(P_{\mathrm{H}}\right)$ and Fisher's exact test $\left(P_{\mathrm{E}}\right)$ (see Table 1 ). Of the 13 loci, one (AGLA17) exhibited a significant $(P<0.05)$ deficit of heterozygosity and all the other 12 loci exhibited a significant $(P<0.05)$ excess in genetic diversity relative to the expected values; these patterns are consistent with directional and balancing selection, respectively. The 12 loci generated average $P$ values significantly (Student's $t$ test: $\overline{P_{H}}=0.020, t=-5.65, P<0.0001 ; \overline{P_{E}}=0.014, t=$ -5.69, $P<0.0001$ ) below than the expected median value of 0.5 . However, average $P$ values of 0.313 for $P_{\mathrm{H}}$ $(t=-4.63, P>0.1)$ and 0.232 for $P_{\mathrm{E}}(t=-8.69, P>0.1)$ were observed in the remaining 38 loci which were not under selection. The observation provided further evidence that selection affected genetic diversity at the microsatellites under selection.

The results of the analyses with the FDIST2 program are presented in Table 1 and Figure 2a. This summarystatistic method, based on simulated and observed $F_{\mathrm{ST}}$ values, identified four loci (SOD1, BMS2461, DIK5019 and AGLA17) as outliers showing footprints of selection in the analyses, including all 10 populations, at the $5 \%$ significance level. Of the four significant loci, three (SOD1, BMS2461 and DIK4519) with higher $F_{\mathrm{ST}}$ values indicated a sign of directional selection and one locus (AGLA17) appearing in the lower tail of the $F_{\mathrm{ST}}$ distribution suggested a signature potentially affected by balancing selection (Figure $2 \mathrm{a}$ ). In the Bayesian $F_{\mathrm{ST}}$-test (Figure 2b), which was based on a hierarchical regression model, three loci (HEL5, DIK4591and SOD1) were 


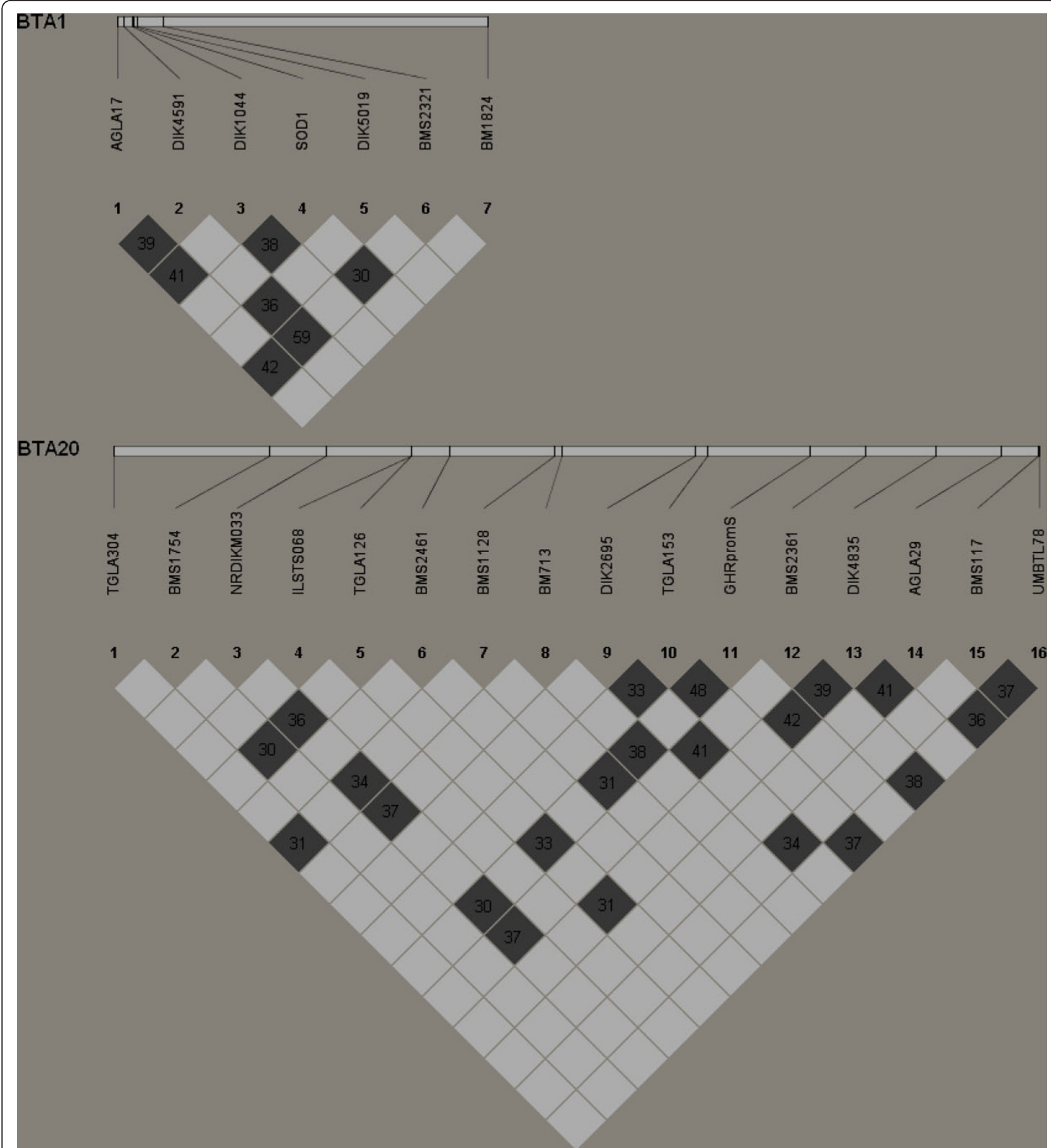

Figure 1 Detailed view of the extent and significance of LD in the cattle populations using the Haploview 4.0 program. Numbers in the blocks indicate the percentage of the LD metric $D^{\prime}$ values $>0.3$; shadings indicate Fisher's exact test significance levels: white, $P>0.05$; light shading, $P<0.05$.

detected as being directionally selected and two (AGLA17 and TGLA227) as under balancing selection. Overall, across all the populations, two loci, AGLA17 and $S O D 1$, exhibited the strongest evidence of selection with all three statistical approaches, which provided good support to their status as outliers due to selection. Two loci (DIK5019 and TGLA227) exhibited significant departure from the neutral expectations in two out of the three selection tests. Furthermore, 12 loci (AGLA29, BMS2361, BM2113, ETH10, ETH225, CSSM66, ETH152, 

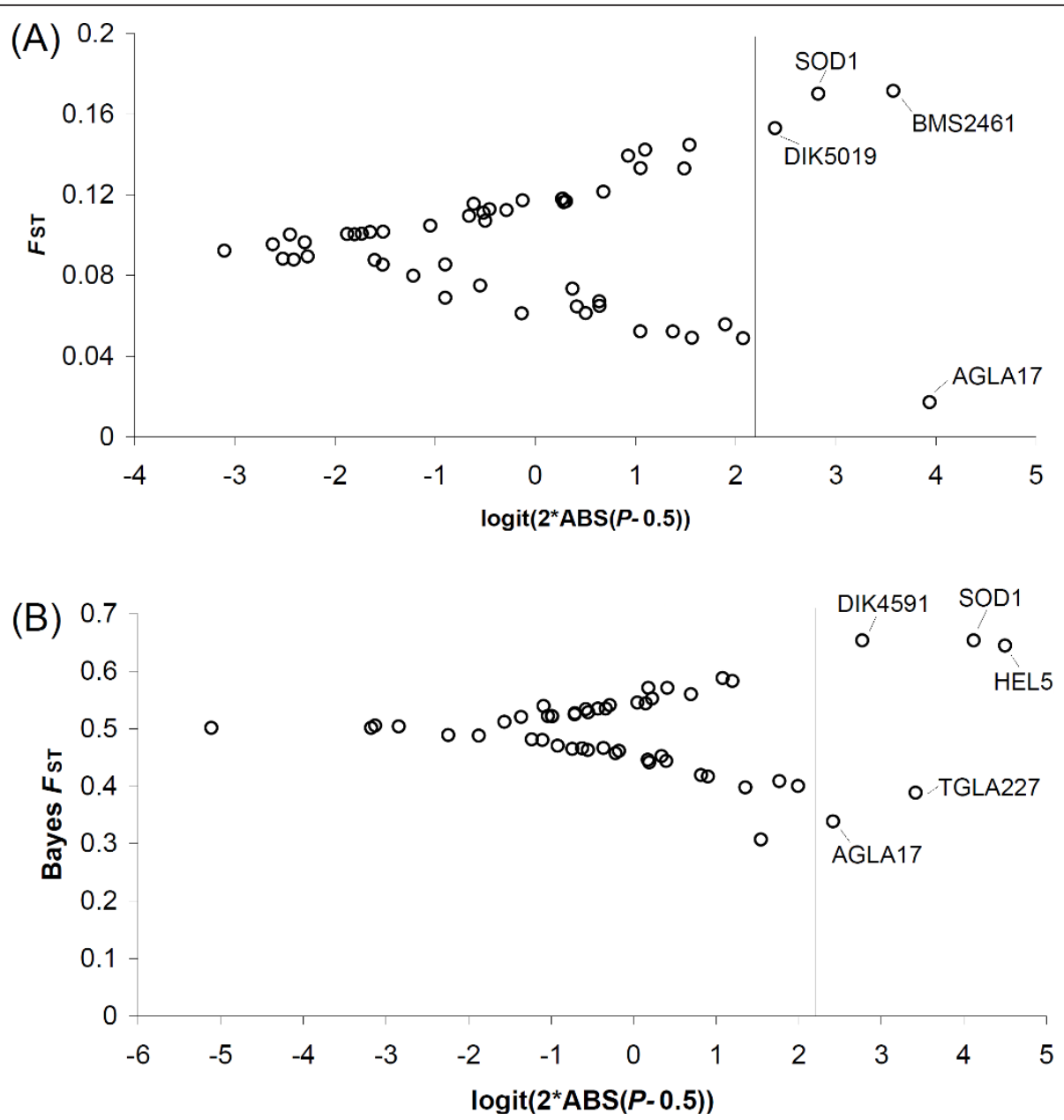

Figure 2 Results of (A) the FDIST2 and (B) BAYESFST tests. The solid lines indicate the critical cutoff for the $P$-value at the 0.05 level.

HAUT24, CSRM60, BMS2461, HEL5 and DIK4591) can be regarded as candidates affected by selection, but were revealed only in one of the three tests. Interestingly, according to ENSEMBL cow genome http://www. ensembl.org/Bos_taurus/Info/Index the significant locus AGLA17 under balancing selection was about $1.78 \mathrm{cM}$ upstream from the candidate locus for $P O L L$, whereas locus $S O D 1$ under directing selection was located about $3.87 \mathrm{cM}$ downstream from the candidate locus. It should be noted that the $F_{\mathrm{ST}}$-based tests of selection are prone to false positives because of sensitivity to demographic history [51], heterozygosity among loci in mutation rate [52] and locus-specific phenomena not related to selection [48]. Nevertheless, we expect the set of loci identified by $F_{\mathrm{ST}}$-based tests to be enriched for the true positives in further tests.

Tests for selection for pairwise populations

Since each of the five tests used above relies on somewhat different assumptions, loci that are repeatedly found to be outside the range expected for neutrality are extremely good candidates for markers under selection. Moreover, LD is known to be extremely high for the six BTA1 microsatellites near the candidate gene affecting the presence or absence of horns in Bos taurus, thus the region under selection is likely to be quite wide. Despite the possible presence of a few false positives, the full set of seven loci (SOD1, BMS2461, DIK5019, HEL5, DIK4591, TGLA227 and AGLA17) was used for further analyses. The $\ln R \theta$ methods $(\ln R H$, $\ln R \mathrm{~V}$ and $\left.\ln R \theta^{\prime}\right)$ use heterozygosity or variance difference, rather than population divergence, to test for selection. Significant results for the $\ln R \theta$ tests for selective sweeps involve the two loci (AGLA17 and SOD1) detected by the Ewens-Watterson test and the $F_{\mathrm{ST}}$-based tests for pairwise combinations $(n=12)$ of three native Finnish cattle populations and four old native populations from Russia and Ukraine (Table 2).

Significant results for selective sweeps at loci AGLA17 and $S O D 1$ were obtained for 12 pairwise population 
comparisons for each of the three different measures of $\ln R \theta$ (Table 2). Of the pairwise comparisons, a total of 28 and 26 significant $(P<0.05)$ or very significant $(P<$ $0.01)$ results were observed at $A G L A 17$ and SOD1, respectively, in the three tests. Both loci (AGLA17 and $S O D 1)$ appeared in all three different measures of $\ln R \theta$ for eight or more comparisons (Table 2), that is, $\ln R \theta$ $\left(\ln R H, \ln R V\right.$ and $\left.\ln R \theta^{\prime}\right)$ values deviating by more than 1.96 standard deviations from the mean. Accordingly, the pairwise comparisons between either of Eastern Finncattle and Western Finncattle and populations of Yakutian, Kholmogory and Ukrainian Grey were significant for all three estimators. All the comparisons between populations yielded at least two significant results for the three estimators. In total, 54 (75\% 54/72) significant comparisons involved AGLA17 or SOD1 in the comparisons between Finnish native populations (Northern Finncattle, Eastern Finncattle and Western Finncattle) vs. the native populations from Russia and Ukraine (Istoben, Ukrainian Grey, Kholmogory and Yakutian Cattle), which suggested that selective sweeps had taken place in the Finnish native populations.

\section{Tests for selection within the Finnish native populations}

The coalescent simulation, which was based on a population split model [49], was performed with the DetSel program within the Finnish native populations with very similar demographical backgrounds (Eastern Finncattle, Northern Finncattle and Western Finncattle). Among the six BTA1 microsatellites around the candidate loci, all are polymorphic in the three populations involved in the pairwise-subpopulation comparison. In the pairwise comparison between definitely polled $(n=19)$ and horned $(n=19)$ cattle, loci AGLA17 and SOD1 were significantly outside the $99 \%$ confidence interval (Figure 3), while locus DIK4591 fell slightly outside the $95 \%$ confidence envelope in the three comparisons, which are thus considered as false positives, i.e., the locus was detected as an outlier because of the $5 \%$ type I error. The outlier behavior for loci $A G L A 17$ and SOD1 was deemed to be the result of strong local effects of hitchhiking selection.

\section{Discussion}

In this study, besides 28 microsatellites on other cattle autosomes used as a reference set of markers, seven microsatellites on BTA1 and 16 on BTA20 around candidate loci were screened for the footprints of selection among 10 cattle populations with divergent horn or production traits. Across different statistical analyses, a highly divergent pattern of genetic differentiation and large differences in levels of variability were revealed at the loci SOD1 and AGLA17 among populations, which was inconsistent with neutral expectations. The results indicated divergent 'selective sweeps' at AGLA17 and $S O D 1$, probably caused by selection of the closely-linked candidate loci for the horned/polled trait, e.g. the POLL gene.

\section{Evidence of selection of microsatellites surrounding the POLL gene}

Because revealing outlier loci in genome scans currently depends on statistical tests, one of the main concerns is to highlight truly significant loci while minimizing the detection of false positives [44]. Using a multilocus scan of differentiation based on microsatellite data, we compared three different methods that aimed at detecting outliers from simulated neutral expectations: 1) the Ewens-Watterson method $[44,45], 2)$ the FDIST2 method [9], and 3) a BAYESFST method [12]. Outliers were identified for 15 loci using a 5\% threshold, which was robust across methods for two loci (SOD1 and AGLA17). The locus SOD1 presented a higher

Table 2 Estimates of $\ln R V$, $\ln R H$ and $\ln R \theta^{\prime}$ for the pairwise comparisons

\begin{tabular}{|c|c|c|c|c|c|c|}
\hline \multirow[t]{2}{*}{ Pairwise comparison } & \multicolumn{2}{|c|}{ InRV } & \multicolumn{2}{|c|}{ InRH } & \multicolumn{2}{|c|}{$\ln R \theta^{\prime}$} \\
\hline & AGLA17 & SOD1 & AGLA17 & SOD1 & AGLA17 & SOD1 \\
\hline Eastern Finncattle - Istoben & * & * & n.s. & n.s. & * & n.s. \\
\hline Eastern Finncattle - Yakutian & * & ** & * & ** & ** & * \\
\hline Eastern Finncattle - Ukrainian Grey & $* *$ & ** & * & * & $* *$ & * \\
\hline Eastern Finncattle - Kholmogory & * & ** & * & * & * & * \\
\hline Western Finncattle - Istoben & $* *$ & * & ** & $* *$ & * & * \\
\hline Western Finncattle - Yakutian & ** & ** & * & * & * & ** \\
\hline Western Finncattle - Ukrainian Grey & * & * & ** & * & * & * \\
\hline Western Finncattle - Kholmogory & * & * & * & * & * & ** \\
\hline Northern Finncattle - Istoben & * & n.s & * & n.s. & n.s. & * \\
\hline Northern Finncattle - Yakutian & * & n.s. & n.s. & * & n.s. & n.s. \\
\hline Northern Finncattle - Ukrainian Grey & $* *$ & * & n.s. & n.s. & n.s. & n.s. \\
\hline Northern Finncattle - Kholmogory & * & n.s. & n.s. & * & n.s. & n.s. \\
\hline
\end{tabular}

* Significance $P<0.05$, ** $P<0.01$, n.s., not significant 


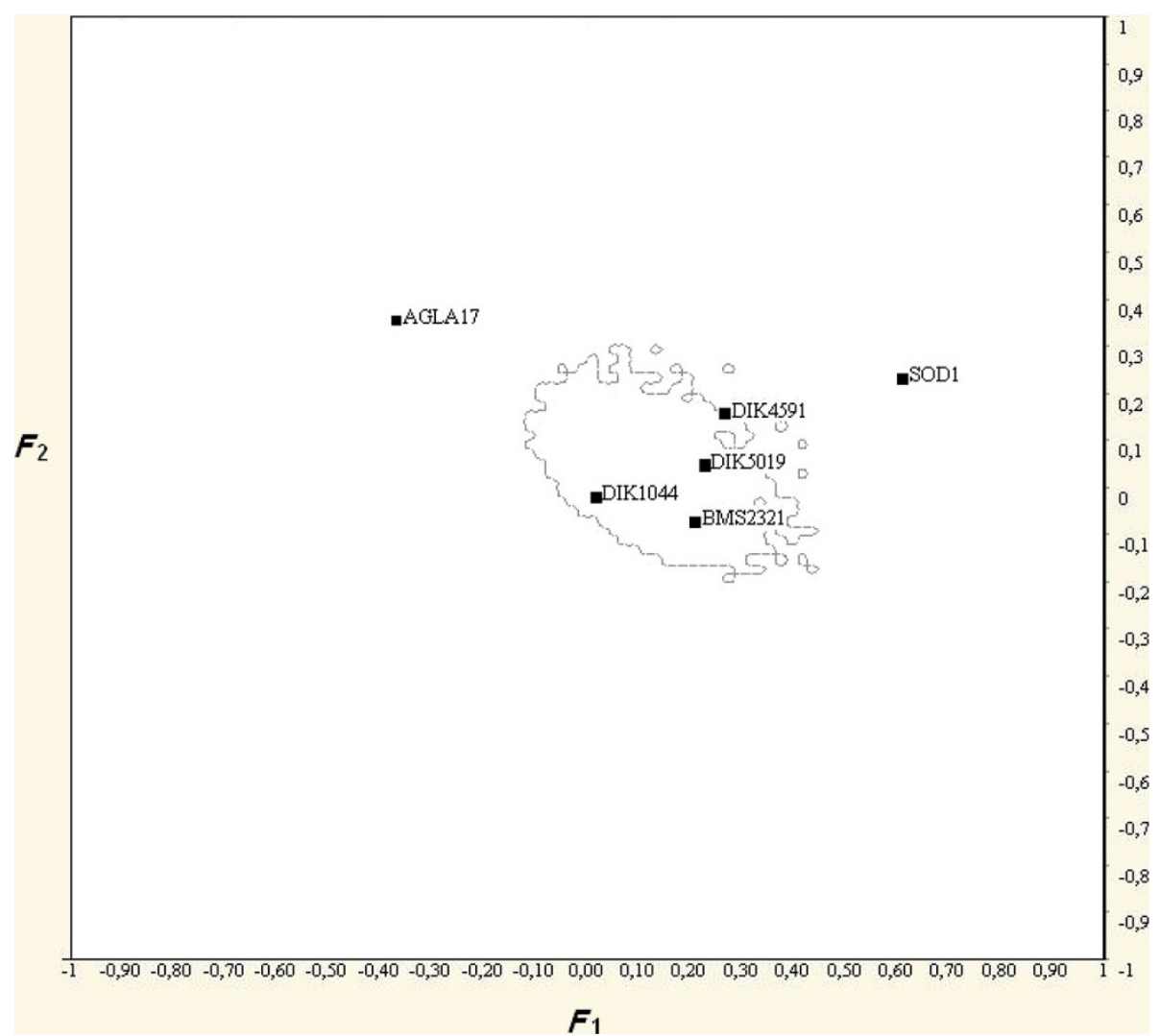

Figure 3 Pairwise comparison of Finnish native cattle populations performed with DetSel. The test was at the $95 \%$ confidence envelope: plot of $F_{2}$ against $F_{1}$ estimates for the subpopulation pair polled vs. horned.

differentiation $\left(F_{\mathrm{ST}}\right.$ value) than expected, suggesting that it could have been affected by the action of diversifying selection among homogeneous gene pools and populations. In contrast, the locus AGLA17 presented a lower genetic differentiation than expected, which could represent signatures of homogenizing selection among populations and/or balancing selection within populations. All three methods identified loci SOD1 and AGLA17 as good candidates for selection on the polled trait. However, several significant loci were detected only by one or two of the tests and thus could not be accepted as reliable outliers with the remaining tests. The results obtained by the three methods are not totally consistent, probably because of the difference in statistical power using multiple measures of variability, each of which measures different parameters and relies on different assumptions, e.g. heterozygosity and variance in allele size [48], as detailed in e.g. [53-55].

Besides the global analyses, detection of outlier loci was also done using pairwise analyses. This helped to reveal loci with a major overall effect as well as loci responding with different strengths to artificial selection on the individual populations. Among the population chosen for the pairwise analyses, the $\ln R \theta(\ln R \mathrm{~V}, \ln R \mathrm{H}$ and $\left.\ln R \theta^{\prime}\right)$ tests yielded a high number of significant $(P<0.05)$ results at SOD1 and AGLG17 according to the three estimators of $\ln R \theta$ (Table 2). This finding conforms well to the previous results of selective sweeps associated with hitchhiking selection with one or more genes with locally beneficial mutations. Although there is difference in the statistical power to detect selection, as discussed in $[6,48,56]$, the three estimators of $\ln R \theta$ provide additional robust evaluation of potential selective sweeps for the pairwise population comparisons.

Neutrality tests for microsatellites focus mainly on unlinked loci and are based on either population differentiation $\left(F_{\mathrm{ST}}\right)$ or reduced variability $(\ln R \theta)$. Our proposed tests consider $\ln R \theta$ of several linked loci for the inference of selection. While the single-locus $\ln R \theta$-test is largely independent of the demographical past, the additional power of linked loci is balanced by the cost of an increasing dependence of the demographic past due to the fact that LD is extremely sensitive to the demographic history. Thus, pairwise analyses between sub-populations may decrease the demographic effects in accounting for the selection. As indicated in Figure 3, the great majority of loci always fall in the confidence region of the conditional pairwise-subpopulation 
distributions of branch length estimates, while some loci do not. Overall, we identified two loci $(S O D 1$ and AGLA17) that were probably subject to selection in the three Finnish native populations. Thus, we concluded that the distribution of variability at these loci could have been shaped by forces other than demographic effects e.g. genetic drift. Although the locus DIK4591 was located on the edge or fell just outside the high probability region of the expected conditional distribution in the Finnish native populations, we must be cautious about the locus because the estimation of $F_{\mathrm{i}}$ parameters is discontinuous as a result of the discrete nature of the data, i.e. the allele counts (e.g. [7]). However, it is worth noting that not all significant loci detected by other methods could be accepted as trustworthy outliers with DetSel due to technical constraints, which means that if a locus is monomorphic in one population of the pair analyses with DetSel are not possible.

Tests to detect outlier loci that deviate from neutral expectation cannot identify false positives (type I errors). Thus, we conducted the three different neutrality tests (the Ewens-Watterson test, the FDIST test and the BAYESFST test), setting a 95\% $P$ level criterion to identify loci under selection pressure, at which the expected number of false positive loci is $51 \times 0.05=2.55$. We still found 13, four and five outlier loci, respectively, indicating that at least some of the outlier loci are unlikely to be false positives. As suggested by [5], a practical approach to strengthen the candidate status of identified outlier loci is to apply two or more neutrality tests simultaneously based on different assumptions and parameter estimation and only consider outlier loci that are supported by several methods for subsequent validation steps. Thus, the fact that some loci are identified by one neutrality test, but not by others, suggests that their status as candidate loci under selection must be regarded with considerable caution. However, significant deviations from neutrality expectation using multiple tests do not necessarily mean that a particular locus has been affected by hitchhiking selection. In this case, we applied three different pairwise population neutrality tests in 12 separate comparisons using two loci (across the populations: $3 \times 12 \times 2=72$ separate tests). This is expected to result in approximately four false positives at the $95 \%$ $P$ level. The fact that we observed as many as 54 deviations (Table 2) at the 95\% P level indicates that it is unlikely that all the outliers identified by pairwise analyses are due to type I errors. Moreover, no locus showed only one significant deviation in one pairwise population comparison (see Table 2). Therefore, it can be considered that the approach was quite robust and conservative in the detection of the effects of hitchhiking selection, particularly when additional pairwise analyses were applied.

\section{Interpretation of the outlier loci and caveats}

Actually microsatellites are unlikely to be the target of selection, but are merely tightly linked to the candidate genes. Since the microsatellites used are located close to some functional candidate genes (or QTLs) on the same chromosome, this indicates a high probability that one or several good candidate genes (or QTLs) is/are tightly linked to some of the microsatellites. In many of the cases examined to date, selective sweeps have affected only a very small region, potentially containing only one or a few genes, except in the case of extremely strong selection (see [57]). Empirical studies indicate that the negligible LD between a hitchhiking locus and a candidate gene underlying selection varied from tens of bp (e.g. [55]) to tens or even hundreds of kb (see [58,59]), which depends on a variety of factors such as the genomic regions (e.g. sex chromosome vs. autosome) and populations (e.g. domesticated vs. wild) investigated, and the type of markers (e.g. EST- or MHC-microsatellites vs. microsatellites) used. It has also been suggested that the LD between loci and candidate genes affected by selection is determined mainly by the strength of selection, local recombination rate, population history, and the age of the beneficial allele [60]. Whatever the reason, significant LD was detected with inter-marker genomic distances between $c a .1100 \mathrm{~kb}$ and $c a .10300 \mathrm{~kb}$ in this study (see Figure 1), a considerably wider interval than reported previously.

We detected two microsatellite loci (AGLA17 and $S O D 1)$ probably linked to the candidate gene for the polled trait in the populations investigated. The polled trait is an autosomal dominant trait in cattle and to date the genes controlling this trait have not been specifically identified. However, the gene causing the absence of horns is known to be at the centromeric end of BTA1. Several factors have potentially driven evolution of the functionally important candidate locus including artificial selection and mating system. In Finnish native cattle populations, polled animals were particularly favored during selective breeding. However, we did not detect any locus under selection on BTA20 despite that the fact that several microsatellites including GHRJA surround the growth hormone receptor gene. Growth hormone receptor belongs to the large superfamily of class 1 cytokine receptors. It has various roles in growth, lactation and reproduction in cattle and has been identified as a candidate gene affecting a few key quantitative traits. Therefore, it is not specific to dairy traits but to traits related with growth, lactation and reproduction. Among the cattle populations 
investigated here, no contrasting differences in growth, lactation or reproduction was observed. In addition, a recent study on the evolution of the cytoplasmic domains of the growth hormone receptor gene in Artiodactyla (see [61]) has suggested that possible effects of selective sweeps on growth hormone receptor gene in bovine occurred before domestication and not among the domestic breeds.

Unfortunately, due to the lack of information on the mutation and recombination rates, as well as the effective population size for these data, estimation of the selection coefficient is not possible here (see [59]). Given that the genomic interval of significant LD is comparable with the findings of hitchhiking around two anti-malarial resistance genes in humans [58] and microsatellite hitchhiking mapping in the three-spined stickleback [59], the hitchhiking selection in this genomic region might be fairly strong. Moreover, the availability of genomic resources (e.g. NCBI Bovine Genome Resources; http://www.ncbi.nlm.nih.gov/projects/genome/guide/cow/)in bovine makes it possible to develop more precise approaches with other much more frequent markers such as SNP. Genotyping an additional set of high density SNP between AGLA17 and SOD1 markers in the populations investigated will definitely give more precise information on selection and LD in the region.

Because the populations studied here are not experimental, they differ for many characteristics other than the polled and horned traits. Thus, some of the genetic differentiation could have been due to other selective forces, e.g. pathogens. In addition, since our data violate at least partly the model assumptions of equal population size and migration rates between populations for the FDIST2 test, the outliers from the test alone should be considered with caution although the multiple neutrality tests based on different assumptions and parameter estimation can minimize the possibility of false positives. Moreover, selection is not the only possibility for changes in the distribution of variation to occur at particular loci, reduced variation or increased differentiation can result from chance alone, e.g. genetic drift, bottlenecks or founder events [57]. To obtain clear evidence for selection of these markers, we must analyze nucleotide variations between polled and horned populations.

\section{Conclusions}

Our microsatellite data from northern Eurasian cattle populations empirically indicate a practical approach for identifying the best candidate loci under hitchhiking selection by simultaneously applying multiple neutrality tests based on different assumptions and parameter estimations. By analyzing microsatellite markers adjacent to functional genes, we identified two loci (SOD1 and AGLA17) that are "selection candidate" targets associated with the horned/polled trait in cattle. This result could be further confirmed by using a more densely spaced set of markers. It would also be of great interest to see if similar patterns of selection around the POLL gene are observed in commercial beef breeds such as Australian Brangus, Angus and Hereford breeds, where dehorning and breeding practices for polled cattle have been an accepted part of cattle management for generations. Another future challenge is to verify the signal of artificial selection on the POLL gene, possibly using the next generation sequencing technology to detect the nucleotide variation of the gene between polled and horned cattle. In addition, the approach we have taken in this paper can be easily extended to other cases and marker types. For example, diversity among cattle has been directed by man towards different goals (e.g. draft, milk, meat, fatness, size, color, horn characteristics, behavior, and other characteristics) during many generations of selection. Each of these selection events has potentially left a signature of selection on the genes and their neighboring loci that could be detected by using tests such as we have applied here. As a marker technology, SNP would offer the advantage of higher throughput when scanning the genome for evidence of hitchhiking selection.

\section{Acknowledgements}

The study includes parts of the data sets from projects of SUNARE (Sustainable Use of NAtural REsources; http://www.aka.fi/sunare), Russia In Flux, and N-EURO-CAD (North European Cattle Diversity). The projects were funded by the Academy of Finland, the Ministry of Agriculture and Forestry in Finland, the Nordic Gene Bank for Farm Animals (NGH), and the Nordic Council of Ministers. We also thank Tatyana Kiselyova, Zoya Ivanova, Ruslan Popov, Innokentyi Ammosov, Elena V. Krysova, Nikolai G. Bukarov, Aleksandr D. Galkin, Boris E. Podoba, Ljudmila A. Popova, and Valerij S. Matjukov for their help in collecting the samples.

\section{Authors' contributions}

MHL designed the study, performed the data analysis and wrote the manuscript. TI-T did the laboratory work and contributed to the manuscript writing and data analysis. HL did the laboratory work, contributed to the manuscript writing and data analysis. JK planned and coordinated the whole study, and contributed to the manuscript writing. All the authors read and approved the final manuscript.

\section{Competing interests}

The authors declare that they have no competing interests.

Received: 6 April 2010 Accepted: 6 August 2010

Published: 6 August 2010

\section{References}

1. Kantanen J, Olsaker I, Holm L-E, Lien S, Vilkki J, Brusgaard K, Eythrosdottir E, Danell B, Adalsteinsson S: Genetic diversity and population structure of 20 North European cattle breeds. J Hered 2000, 91:446-457.

2. Li MH, Tapio I, Vilkki J, Ivanova Z, Kiselyova T, Marzanov N, Ćinkulov M, Stojanović S, Ammosov I, Popov R, Kantanen J: Genetic structure of cattle populations (Bos taurus) in northern Eurasia and the neighboring Near 
Eastern regions: implications for breeding strategies and conservation. Mol Ecol 2007, 16:3839-3853.

3. Li MH, Adamowicz T, Switonski M, Ammosov I, Ivanova Z, Kiselyova T, Popov R, Kantanen J: Analysis of population differentiation in North Eurasian cattle (Bos taurus) using single nucleotide polymorphisms in three genes associated with production traits. Anim Genet 2006, 27:390-392.

4. Santucci F, Ibrahim KM, Bruzzone A, Hewit GM: Selection on MHC-linked microsatellite loci in sheep populations. Heredity 2007, 99:240-248.

5. Vasemägi A, Nilsson J, Primmer CR: Expressed sequence Tag-linked microsatellites as a source of gene-associated polymorphisms for detecting signatures of divergent selection in Atlantic Salmon (Salmo salar L.). Mol Biol Evol 2005, 22:1067-1076.

6. Kauer MO, Dieringer D, Schlötterer C: A microsatellite variability screen for positive selection associated with the "Out of Africa" habitat expansion of Drosophila melanogaster. Genetics 2003, 165:1137-1148.

7. Vitalis R, Dawson K, Boursot P: Interpretation of variation across marker loci as evidence of selection. Genetics 2001, 158:1811-1823.

8. Bowcock AM, Kidd JR, Mountain JL Hebert JM, Carotenuto L, Kidd KK, Cavalli-Sforza LL: Drift, admixture, and selection in human evolution: a study with DNA polymorphisms. Proc Natl Acad Sci USA 1991, 88:839-843.

9. Beaumont MA, Nichols RA: Evaluating loci for use in the genetic analysis of population structure. Proc R Soc Lond B Biol Sci 1996, 263:1619-1626.

10. Schlötterer $C$ : Towards a molecular characterization of adaptation in local populations. Curr Opin Genet Dev 2002, 12:683-687.

11. Porter $\mathrm{AH}$ : A test for deviation from island-model population structure. Mol Ecol 2003, 12:903-915.

12. Beaumont MA, Balding DJ: Identifying adaptive genetic divergence among populations from genome scans. Mol Ecol 2004, 13:969-980.

13. Wiehe T, Nolte D, Zivkovic D, Schlötterer C: Identification of selective sweeps using a dynamically adjusted number of linked microsatellites. Genetics 2007, 175:207-218.

14. Lewontin RC, Krakauer J: Distribution of gene frequency as a test of the theory of the selective neutrality of polymorphisms. Genetics 1973, 74:175-195.

15. Nei M, Maruyama T: Lewontin-Krakauer test for neutral genes. Genetics 1975, 80:395.

16. Nielsen EE, Hansen MM, Meldrup D: Evidence of microsatellite hitchhiking selection in Atlantic cod (Gadus morhua L.): implications for inferring population structure in nonmodel organisms. Mol Ecol 2006, 15:219-3229.

17. Hansen MM, Skaala Ø, Jensen LF, Bekkevold D, Mensberg K-LD: Gene flow, effective population size and selection at major histocompatibility complex genes: brown trout in the Hardenger Fjord, Norway. Mol Ecol 2007, 16:1413-1425.

18. Nielsen EE, Kenchington E: Prioritising marine fish and shellfish populations for conservation: a useful concept? Fish and Fisheries 2001, 2:328-343

19. Beaumont MA: Adaptation and speciation: What can Fst tell us? Trends Ecol Evol 2005, 20:435-440.

20. Guinand B, Lemaire C, Bonhomme F: How to detect polymorphisms undergoing selection in marine fishes? A review of methods and case studies, including flatfishes. J Sea Res 2004, 51:167-182.

21. Georges M, Drinkwater R, King T, Mishra A, Moore SS, Nielsen D, Sargeant LS, Sorensen A, Steele MR, Zhao X, Womack JE, Hetzel J: Microsatellite mapping of a gene affecting horn development in Bos taurus. Nat Genet 1993, 3:206-210.

22. Brenneman RA, Davis SK, Sanders JO, Burns BM, Wheeler TC, Turner JW, Taylor JF: The polled locus maps to BTA1 in Bos indicus $\times$ Bos taurus cross. J Hered 1996, 87:156-161

23. Harlizius B, Tammen I, Eichler K, Eggen A, Hetzel DJS: New markers on bovine chromosome 1 are closely linked the polled gene in Simmental and Pinzgauer cattle. Mamm Genome 1997, 8:225-227.

24. Li MH, Kantanen J: Genetic structure of Eurasian cattle (Bos taurus) based on microsatellites: clarification for their breed classification. Anim Genet 2010, 41:150-158.

25. Schmutz SM, Marquess FLS, Berryere TG, Moker JS: DNA assisted selection of the polled condition in Charolais cattle. Mamm Genome 1995, 6:710-713
26. McKay SD, White SN, Kata SR, Loan R, Womack JE: The bovine 5' AMPK gene family: mapping and single nucleotide polymorphism detection. Mamm Genome 2003, 14:853-858.

27. Viitala S, Schulman N, De Koning -J, Elo K, Kinos R, Virta A, Virta J, MäkiTanila A, Vilkki J: Quantitative trait loci affecting milk production traits in Finnish Ayrshire dairy cattle. J Dairy Sci 2003, 86:1828-1836.

28. Ashwell MS, Heyen DW, Weller Jl, Ron M, Sonstegard TS, Van Tassell CP, Lewin HA: Detecting quantitative trait loci influencing conformation traits and calving ease in Holstein-Friesian cattle. J Dairy Sci 2005, 88:4111-4119.

29. Schrooten C, Bovenhuis H, Coppieters W, van Arendonk JA: Whole genome scan to detect quantitative trait loci for conformation and functional traits in dairy cattle. J Dairy Sci 2000, 8:795-806.

30. Ashwell MS, Tassell CPV, Sonstegard TS: A genome scan to identify quantitative trait loci affecting economically important traits in a US Holstein population. J Dairy Sci 2001, 84:2535-2542.

31. Arranz JJ, Coppieters W, Berzi P, Cambisano N, Grisart B, Karim L, Marcq F, Moreau L, Mezer C, Riquet J, Simon P, Vanmanshoven P, Wagenaar D, Georges M: A QTL affecting milk yield and composition maps to bovine chromosome 20: a confirmation. Anim Genet 1998, 29:107-115.

32. Medugorac I, Medugorac A, Russ I, Veit-kensch CE, Taberlet P, Luntz B, Mix HM, Förster M: Genetic diversity of European cattle breeds highlights the conservation value of traditional unselected breeds with high effective population size. Mol Ecol 2009, 18:3394-3410.

33. Tapio I, Värv S, Bennewitz J, Maleviciute J, Fimland E, Grislis Z Meuwissen THE, Miceikiene I, Olsaker I, Viinalass H, Vilkki J, Kantanen J: Prioritization for conservation of Northern European cattle breeds based on analysis of microsatellite data. Conserv Biol 2006, 20:1768-1779.

34. Ihara N, Takasuga A, Mizoshita K, Takeda H, Sugimoto M, Mizoguchi Y, Hirano T, Itoh T, Watanabe T, Reed KM, Snelling WM, Kappes SM, Beattie CW, Bennett GL, Sugimoto Y: A comprehensive genetic map of the cattle genome based on 3802 microsatellites. Genome Res 2004, 14:1987-1998.

35. Blott S, Kim J J, Moisio S, Schmidt-Küntzel A, Cornet A, Berzi P, Cambisano N, Ford C, Grisart B, Johnson D, Karim L, Simon P, Snell R, Spelman R, Wong J, Vilkki J, Georges M, Farnir F, Coppieters W: Molecular dissection of a quantitative trait locus: a phenylalanine-to-tyrosine substitution in the transmembrane domain of the bovine growth hormone receptor is associated with a major effect on milk yield and composition. Genetics 2003, 163:253-266.

36. Weir BS, Cockerham CC: Estimating F-statistics for the analysis of population structure. Evolution 1984, 38:1358-1370.

37. Goudet J: FSTAT, a program to estimate and test gene diversities and fixation indices version 2.9.3. 2002 [http://www2.unil.ch/popgen/ softwares/fstat.htm], Updated from Goudet (1995).

38. Gaunt TR, Rodriguez S, Zapata C, Day INM: MIDAS: software for analysis and visualisation of interallelic disequilibrium between multiallelic markers. BMC Genomics 2006, 7:227.

39. Li MH, Merilä J: Extensive linkage disequilibrium in a wild bird population. Heredity 2010, 104:600-610.

40. Schneider S, Roessli D, Excoffier L: Arlequin Version 2.000: A Software for Genetic Data Analysis. Genetics and Biometry Laboratory, University of Geneva, Geneva 2000.

41. Slatkin M: A measure of population subdivision based on microsatellite allele frequencies. Genetics 1995, 139:457-462.

42. Barrett JC, Fry B, Maller J, Daly MJ: Haploview: analysis and visualization of LD and haplotype maps. Bioinformatics 2005, 21:263-265.

43. Raymond M, Rousset F: Genepop (version1.2): population genetics software for exact tests and ecumenicism. J Hered 1995, 86:248-249.

44. Ewens W: The sampling theory of selectively neutral alleles. Theor Popul Biol 1972, 3:87-112

45. Watterson G: The homozygosity test of neutrality. Genetics 1978 , 88:405-417.

46. Bonin A, Taberlet P, Miaud C, Pompanon F: Explorative genome scan to detect loci for adaptation along a gradient of altitude in the common frog. Mol Biol Evol 2006, 23:773-783.

47. Beaumont MA: Detecting population expansion and decline using microsatellites. Genetics 1999, 153:2013-1029. 
48. Schlötterer C, Dieringer D: A novel test statistics for the identification of local selective sweeps based on microsatellite gene diversity. selective sweeps Eurekah.com and Klüver Academic/Plenum Publishers, Georgetown, TX, USANurminski D 2005, 55-64.

49. Vitalis R, Dawson K, Boursot P, Belkhir K: DetSel 1.0: A computer program to detect markers responding to selection. J Hered 2003, 94:429-431.

50. Vigouroux Y, McMullen M, Hittinger $C T$, Houchins K, Schulz L, Kresovich S, Matsuoka $Y$, Doebley J: Identifying genes of agronomic importance in maize by screening microsatellites for evidence of selection during domestication. Proc Natl Acad Sci USA 2002, 99:9650-9655.

51. Whitlock MC, McCauley DE: Indirect measures of gene flow and migration: FST not equal to $1 /(4 \mathrm{Nm}+1)$. Heredity $1999,82: 117-125$.

52. Storz JF, Payseur A, Nachman MW: Genome scans of DNA variability in humans reveal evidence for selection sweeps outside Africa. Mol Biol Evol 2004, 9:1800-1811

53. Eveno E, Collada C, Guevara MA, Leger V, Soto A, Diaz L, GonzalezMartinez SC, Cervera MT, Plomion C, Garnier-Gere PH: Contrasting patterns of selection at Pinus pinaster Ait. Drought stress candidate genes as revealed by genetics differentiation analyses. Mol Biol Evol 2007, 25:417-437.

54. Bryja J, Charbonnel N, Berthier K, Galan M, Cosson JF: Density-related changes in selection pattern for major histocompatibility complex genes in fluctuating populations of voles. Mol Ecol 2007, 16:5048-5097.

55. Vasemägi A, Primmer CR: Challenges for identifying functionally important genetic variation: the promise of combining complementary research strategies. Mol Ecol 2005, 14:3623-3642.

56. Ithe S, Ravaoarimanana I, Thomas M, Tautz D: An analysis of signatures of selective sweeps in natural populations of the house mouse. Mol Biol Evol 2006, 23:790-797.

57. Kane NC, Rieseberg LH: Selective sweeps reveal candidate genes for adaptation to drought and salt tolerance in common sunflower, Helianthus annuus. Genetics 2007, 175:1823-1834.

58. Nash D, Nair S, Mayfong M, Newton PN, Guthmann J-P, Nosten F, Anderson TJC: Selection strength and hitchhiking around two antimalarial resistance genes. Proc R Soc Lond B Biol Sci 2005, 272:1153-1161.

59. Mäkinen HS, Shikano T, Cano JM, Merilä J: Hitchhiking mapping reveals a candidate genomic region for natural selection in three-spined stickleback chromosome VIII. Genetics 2008, 178:453-465.

60. Nordborg M, Tavaré S: Linkage disequilibrium: what history has to tell us. Trends Genet 2006, 18:83-90.

61. Iso-Touru T, Kantanen J, Li MH, Gizejewski Z, Vilkki J: Divergent evolution in the cytoplasmic domains of PRLR and GHR genes in Artiodactyla. BMC Evol Biol 2009, 9:172.

doi:10.1186/1297-9686-42-32

Cite this article as: Li et al:: A microsatellite-based analysis for the detection of selection on BTA1 and BTA20 in northern Eurasian cattle (Bos taurus) populations. Genetics Selection Evolution 2010 42:32.

\section{Submit your next manuscript to BioMed Central and take full advantage of:}

- Convenient online submission

- Thorough peer review

- No space constraints or color figure charges

- Immediate publication on acceptance

- Inclusion in PubMed, CAS, Scopus and Google Scholar

- Research which is freely available for redistribution

Submit your manuscript at www.biomedcentral.com/submit
Biomed Central 